\title{
The Structure of the Electric Double Layer of Macromolecules Suspended in Human Cerebrospinal Fluid
}

\author{
Leszek Herbowski ${ }^{1 *}$ and Henryk Gurgul ${ }^{2}$
}

${ }^{1}$ Neurosurgery Department, Public Provincial Hospital, Poland

${ }^{2}$ Institute of Physics, University of Szczecin, Poland

\begin{abstract}
The cerebrospinal fluid is a dilute suspension of large colloidal macroparticles such as protein molecules and cells. Based on microscopic observations of cerebrospinal fluid samples and some theoretical data the authors could develop a schematic structure of electric double layer around the biomolecules suspended in cerebrospinal fluid. Numerical results show that the averaged diameter of the observed macroparticles is $5,1 \mu \mathrm{m}$. We could observe Brownian motions of large biomolecules as a result of thermal nanoparticles movements. Understanding ions composition of cerebrospinal fluid we could state that the compact Stern layer consists of sodium cations and the Gouy layer of chloride anions. Our calculations reveal that the thickness of the Stern layer surrounding macroparticles in cerebrospinal fluid is $0,366 \mathrm{~nm}$.
\end{abstract}

Keywords: Stern layer; Optical microscopy; Brownian movement; Biomolecules

\section{Introduction}

The cerebrospinal fluid (CSF) is hydrophilic colloidal fluid circulating around the brain and spinal cord [1]. Normal CSF contains up to 5 white blood cells per $\mathrm{mm}^{3}$ and circa 563 different varieties of peptides and 581 proteins suspended all together in the bulk electrolyte solution. According to Ohshima's theory of electrophoresis we can regard proteins and biological cells as hard particles [2-4]. Both protein molecules and cells occurring in CSF are electronegative macroparticles because of conversion of amino acid side chains to carboxylate anions at physiological $\mathrm{pH} 7,33$ of CSF and negatively charged sialic acid residues on the membrane surface, respectively [5]. At the junction of the particle-electrolyte solution interface there appears the double electrical layer and on the basis of Gouy and Stern models a particle is surrounded by the inner Stern layer of stagnant ions and the external diffuse Gouy layer of mobile counterions [6-9]. The full description of the electrochemical potential phenomena on the surface of biomolecules was demonstrated by Dukhin [10]. Generally, the Stern layer is a thin layer of one molecule diameter whereas the diffuse layer size is up to hundreds nanometers [11].

In this work, optical microscopy as a tracking system has been used to determine the properties of individual biomolecules suspended in the CSF. On the basis of experimental and theoretical data we calculated the size of biomolecules suspended in the CSF and then the thickness of the Stern layer. Thus, the structure of EDL around the biomolecules could be presented.

So far, molecular electrokinetic processes such as Brownian movements and Stern layer occurring in CSF have been described by authors on the surface of the human arachnoid membrane [12]. A preliminary report of this work was presented at the SPIE International Optical Conference [13].

\section{Materials and Methods}

The investigation is a part of the research project Physicochemical processes occurring in cerebrospinal fluid obtained from patients diagnosed with disorders of cerebrospinal fluid circulation and has been conducted in cooperation of the Institute of Physics at the University of Szczecin and the Neurosurgery Department at the Public Provincial Hospital Complex in Szczecin. The authors obtained approval from the
Bioethics Committee of the Regional Medical Council in Szczecin to perform these clinical studies. According to accepted ethical rules in medical researches, we obtained written informed consent in each case in our study. The samples of the cerebrospinal fluid were collected by lumbar puncture during routine diagnostic procedures from 27 patients hospitalized due to suspicion of having normal pressure hydrocephalus. All samples were water-clear and the contents of proteins and cells were in the normal range. In the following step, the sample was placed on the Bürker plate, and then 20 fields of $100 \mu \mathrm{m}$ x $100 \mu \mathrm{m}$ each were analyzed to determine the number and diameter of the particles. The optical analyzis was carried out using the Nikon microscope ECLIPSE 600 connected to a digital camera and a computer equipped with software Lucia v.4.6 by Laboratory Imaging company for picture analysis. The thickness of the Stern layer of the macromolecules suspended in the CSF was estimated by relating surrounding ions to these particles.

\section{Results}

This chapter deals with numerical results obtained from examination of 540 microscopic fields with CSF samples from 27 neurosurgical patients, 12 women and 15 men (mean age 56 years, age range 20 to 81 years). Demographic and clinical data of the patients are presented in Table 1. The observed microscopic pictures of the macroparticles suspended in the CSF are shown in Figure 1.

Biomolecules suspended in the CSF differ in size. In the optical microscopic pictures we recognized 724 particles, from 7 to 148 per patient. The averaged diameter of all observed particles was 5,1 $\pm 2,05$ $\mu \mathrm{m}$ (mean $\pm \mathrm{SD}$ ), varied from $1,7 \mu \mathrm{m}$ to $9,5 \mu \mathrm{m}$. The data in Figure 2 present the average diameter of the particles in each patient. On this

*Corresponding author: Leszek Herbowski, Neurosurgery Department, Public Provincial Hospital, Arkońska 4, 71-455 Szczecin, Poland, E-mail: leszekherbowski@data.pl

Received December 27, 2010; Accepted February 12, 2011; Published February 16, 2011

Citation: Herbowski L, Gurgul H (2011) The Structure of the Electric Double Layer of Macromolecules Suspended in Human Cerebrospinal Fluid. J Neurol Neurophysiol 2:108. doi:10.4172/2155-9562.1000108

Copyright: (c) 2011 Herbowski L, et al. This is an open-access article distributed under the terms of the Creative Commons Attribution License, which permits unrestricted use, distribution, and reproduction in any medium, provided the original author and source are credited. 
occasion we could observe the Brownian movements of the particles suspended in the CSF which are illustrated in Figure 3. Consecutive examples of macroparticles motions in the CSF are shown to reveal the effect of the thermal fluctuations of the electrolyte solvent on the macroparticles.

The large micro-objects observed in the CSF reflect macromolecules, both protein molecules and cells. Therefore, the largest particles with the diameter around $8 \mu \mathrm{m}$ are most probably leukocytes and the smaller macroparticles are aggregated proteins or fragmented cells. The major protein in CSF is albumin with molecular radius of $36 \hat{A}$ and it has a strong negative charge. A negative charge carried on the membrane surface of the leukocytes equals -18 milivolt [5]. Generally, the main CSF macromolecules are electronegative.

The cerebrospinal fluid consists of different ions, both anions $(\mathrm{Cl}$, $\mathrm{HCO}_{3}, \mathrm{PO}_{4}$ ) and cations $\left(\mathrm{Na}, \mathrm{K}, \mathrm{Ca}^{2}, \mathrm{Mg}^{2}\right)$, with total ionic strength about 0,176 . Among these ions, there is a markedly higher amount of $\mathrm{Na}^{+}(0,138 \mathrm{~mol} / \mathrm{L})$ and $\mathrm{Cl}^{-}(0,119 \mathrm{~mol} / \mathrm{L})$ than others (about $0,001-0,04$ $\mathrm{mol} / \mathrm{L}$ ) [1]. Based on a paper of $\mathrm{Li}$ and co-workers, for an electrolyte

\begin{tabular}{|c|c|c|c|}
\hline Patient & Age & Sex & Clinical Diagnosis \\
\hline 1 & 79 & $\mathrm{~F}$ & Internal hydrocephalus \\
\hline 2 & 54 & M & Internal hydrocephalus \\
\hline 3 & 62 & $\mathrm{~F}$ & Internal hydrocephalus \\
\hline 4 & 76 & $M$ & Internal hydrocephalus \\
\hline 5 & 54 & $\mathrm{~F}$ & Internal hydrocephalus + Intraventricular cyst \\
\hline 6 & 52 & M & Internal hydrocephalus \\
\hline 7 & 70 & $\mathrm{~F}$ & Internal hydrocephalus \\
\hline 8 & 34 & M & Internal hydrocephalus \\
\hline 9 & 74 & M & Internal hydrocephalus \\
\hline 10 & 49 & $\mathrm{~F}$ & Internal hydrocephalus \\
\hline 11 & 58 & $\mathrm{~F}$ & Internal hydrocephalus \\
\hline 12 & 60 & M & Internal hydrocephalus \\
\hline 13 & 66 & $\mathrm{~F}$ & Internal hydrocephalus \\
\hline 14 & 52 & $\mathrm{~F}$ & Internal hydrocephalus \\
\hline 15 & 78 & M & Internal hydrocephalus \\
\hline 16 & 64 & M & Internal hydrocephalus \\
\hline 17 & 81 & $\mathrm{~F}$ & Internal hydrocephalus \\
\hline 18 & 31 & M & Internal hydrocephalus \\
\hline 19 & 60 & M & Internal hydrocephalus + Intraventricular cyst \\
\hline 20 & 49 & $\mathrm{~F}$ & Internal hydrocephalus \\
\hline 21 & 57 & M & Internal hydrocephalus + Subarachnoid cyst \\
\hline 22 & 59 & M & Internal hydrocephalus + Spastic paraparesis \\
\hline 23 & 50 & $\mathrm{~F}$ & Internal hydrocephalus \\
\hline 24 & 34 & M & Internal hydrocephalus \\
\hline 25 & 20 & M & Posttraumatic hydrocephalus \\
\hline 26 & 65 & $\mathrm{~F}$ & $\begin{array}{l}\text { Internal hydrocephalus + Intracranial } \\
\text { hypertension }\end{array}$ \\
\hline 27 & 24 & M & Congenital Internal hydrocephalus \\
\hline
\end{tabular}

Table 1: Clinical and demographic characteristics of all 27 neurosurgical patients.

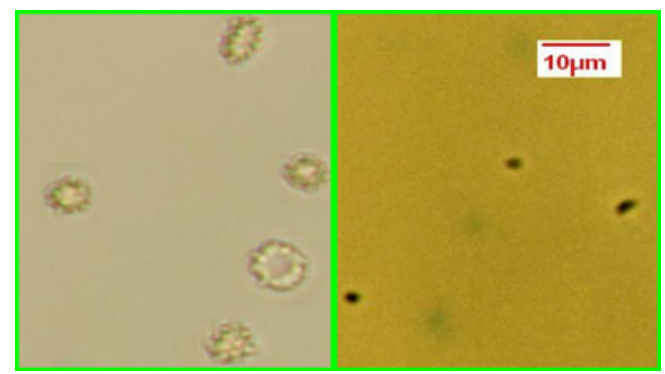

Figure 1: Microscopic slides of the observed macroparticles suspended in cerebrospinal fluid. The diameter of biomolecules on the left side is about $10 \mu \mathrm{m}$ and on the right side $1 \mu \mathrm{m}$.

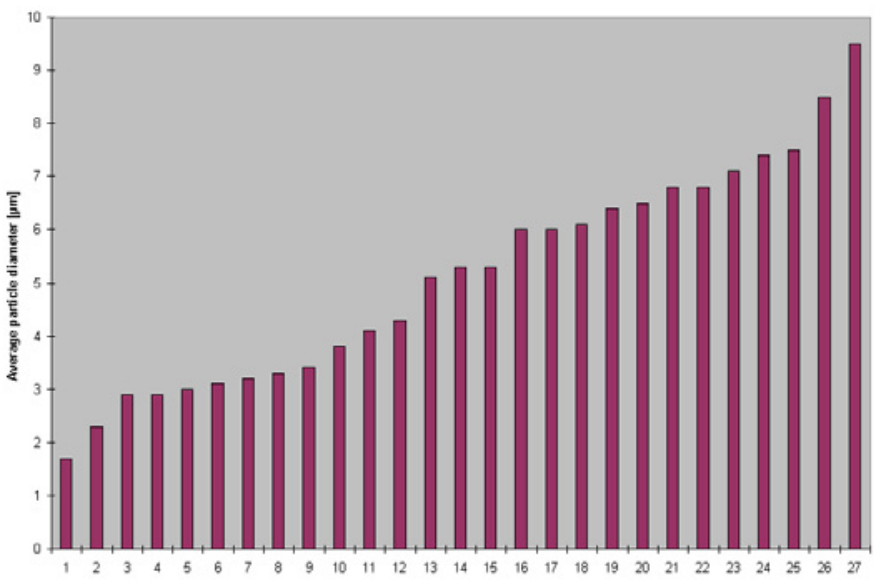

Figure 2: The increasing histogram of the average diameter of the particles suspended in cerebrospinal fluid in all 27 neurosurgical patients.
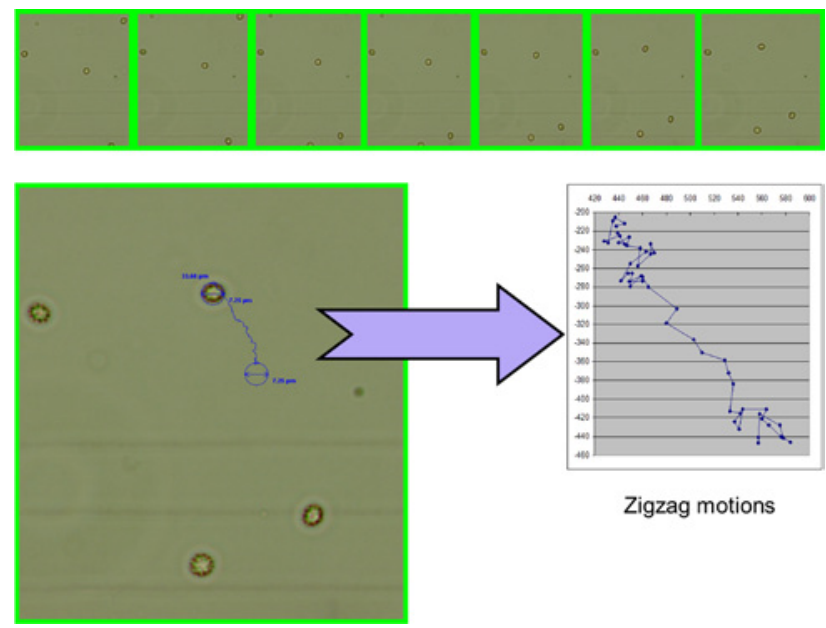

Figure 3: Subsequent microscopic trajectories of colloidal macroparticles of radius $7 \mu \mathrm{m}$ suspended in cerebrospinal fluid. The Brownian motions of biomolecules are the result of thermal fluctuation of non-visible nanoparticles.

concentration is below $10^{-4} \mathrm{~mol} / \mathrm{L}$ there is no adsorption on the solid surface [14]. Therefore, only $\mathrm{Na}^{+}$and $\mathrm{Cl}^{-}$ions concentrations in CSF are sufficient to produce the electric double layer.

Under the conditions described above, the electronegative macroparticles suspended in CSF are surrounded by positive sodium ions which attach firmly and build the Stern layer. This leads then to binding of negative chloride ions and hence to form the diffuse layer. The thickness of the Stern layer of macroparticles suspended in CSF equals the diameter of $\mathrm{Na}^{+}$ion and it is about $0,366 \mathrm{~nm}$ [15]. Figure 4 offers a schematic model of the electric double layer around the macroparticles suspended in the cerebrospinal fluid.

\section{Discussion}

Owing much to the fundamental concept of Smoluchowski electrokinetic theory, the double layer at the junction of two phases was introduced by Helmholtz in 1879 and extended by Gouy and Stern afterwards $[8,16]$. Both an aqueous electrolyte solution and the phospholipid cell surface or protein surface are dielectric media. Deriving from the concept of electrostatics theory, an electric field is formed on the membrane/protein surfaces [5]. As a consequence, the surface potential attracts ions of the opposite charge and repels ions 


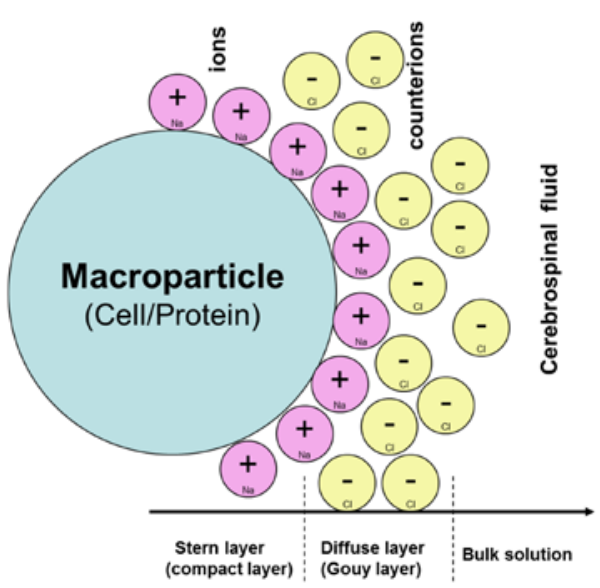

Figure 4: Schematic representation of the electric double layer around the macroparticles suspended in cerebrospinal fluid. The internal Stern layer consists of $\mathrm{Na}^{+}$ions and the external Gouy layer of $\mathrm{Cl}^{-}$ions.

of the same charge. Basing on the standard Stern model, we could present the model of EDL of macromolecules suspended in CSF. In our approach, we excluded the water ions flux into the compact Stern layer, the concept which is now under a great considerations $[17,18]$.

Microscopic examination is the gold standard to analyze biological particles suspended in CSF and this optical method allows for investigating the size of particles with diameter down to $0,4 \mu \mathrm{m}$ [19]. We could analyze the shape and size of particles and observe the movements of the macroparticles occurring in the CSF. Macroparticles motions reflect the Brownian movements of the solvent nanoparticles invisible to optical microscopy. From the microscopic analyzis of the CSF samples the average diameter of the observed macroparticles is $5,1 \mu \mathrm{m}$ (from $1,7 \mu \mathrm{m}$ to $9,5 \mu \mathrm{m}$ ).

Numerous biomedical studies have demonstrated that the thickness of the Stern layer is about $0,2-0,5 \mathrm{~nm}$ and is in relation to the radius of one molecule $[20,21]$. We stated that the macroparticles suspended in the CFS are surrounded by positive sodium ions forming the Stern layer which is strongly attached to the particle surface. Our studies proved that the thickness of the Stern layer equals the diameter of the $\mathrm{Na}^{+}$ion, i.e., $0,366 \mathrm{~nm}$.

\section{Conclusions}

1. The cerebrospinal fluid is a dilute suspension of large colloidal macroparticles (protein molecules, cells) which can be observed by optical microscopy.

2. Based on our observations, the average diameter of macroparticles suspended in cerebrospinal fluid is $5,1 \mu \mathrm{m}$.

3. The electric double layer of macromolecules in cerebrospinal fluid consists of the internal compact $\mathrm{Na}^{+}$ions forming the Stern layer and the external $\mathrm{Cl}^{-}$counterions building the Gouy layer.

4. The thickness of the Stern layer of electric double layer around macromolecules suspended in cerebrospinal fluid is $0,366 \mathrm{~nm}$.

5. By means of the colloidal model of electric double layer by GouyChapman and Stern theories, and on the basis of our observations and theoretical considerations, a graphic structure of electric double layer surrounding macromolecules occurring in cerebrospinal fluid could be demonstrated.

\section{Acknowledgments}

The authors thank Przemek Tytro for his skillful technical support in figures making and Patrycja Herbowska for help in the translation of this manuscript.

\section{References}

1. Robertson DS (2010) The Physical Chemistry of Brain and Neural Cell Membranes: An Overview. Neurochem Res 35: 681-687.

2. Seehusen, DA, Reeves MM, Fomin DA (2003) Cerebrospinal Fluid Analysis Am Fam Physician 68: 1103-1108.

3. Zougman A, Pilch B, Podtelejnikov A, Kiehntopf M, Schnabel C, et al. (2008) Integrated Analysis of the Cerebrospinal Fluid Peptidome and Proteome. J Proteome Res 7: 386-399.

4. Ohshima H (2006) Theory of Colloid and Interfacial Electric Phenomena. Acad Press, London.

5. Wall J, Ayoub F, O'Shea P (1995) Interactions of macromolecules with the mammalian cell surface. J Cell Sci 108: 2673-2682.

6. Lyklema L, van Leeuwen HP, de Keizer A, Vliet M, Cazabat A-M (1995) Fundamentals of interface and colloid science. Vol. II: Solid-Liquid Interfaces. Acad Press, London.

7. Fischer EK (2007) Colloid Dispersions. National Bureau of Standards. Read Books.

8. Hatschek E (2008) An Introduction to the Physics and Chemistry of Colloids. BiblioLife.

9. Strubbe F, Beunis F, Neyts K (2006) Determination of the effective charge of individual colloidal particles. J Colloid Interface Sci 301: 302-309.

10. Dukhin AS (1993) Biospecific mechanism of double layer formation and peculiarities of cell electrophoresis. Colloids Surfaces A: Physicochem Eng Aspects 73: 29-48.

11. Gao Y, Li D (2008) Translational motion of a spherical particle near a planar liquid-fluid interface. J Colloid Interface Sci 319: 344-352.

12. Herbowski L, Gurgul H, Staroń W (2009) Experimental determination of the Stern layer thickness at the interface of the human arachnoid membrane and the cerebrospinal fluid. Z Med Phys 19: 189-192.

13. Staroń W, Herbowski L, and Gurgul H (2007) Optical analysis of suspended particles in the cerebrospinal fluid obtained by puncture from patients diagnosed with the disorders of cerebrospinal fluid (CSF) circulation. Proc SPIE 6609:66091B

14. Li H, Qing CL, Wie SQ, Jiang XJ (2004) An approach to the method for determination of surface potential on solid/liquid interface: theory. $\mathrm{J}$ Colloid Interface Sci 275: 172-176.

15. Allison S, Rasmusson M, and Wall S (2003) The primary electroviscous effect free solution electrophoretic mobility, and diffusion of dilute prolate ellipsoid particles (minor axis $=3 \mathrm{~nm}$ ) in monovalent salt solution. J Colloid Interface Sci 256: 289-297.

16. Delgado AV, Gonzalez-Caballero F, Hunter RJ, Koopal LK, Lyklema J (2007) Measurement and interpretation of electrokinetic phenomena. J Colloid Interface Sci 309: 194-224.

17. Rahnemaie R, Hiemstra T, van Riemsdijk WH (2006) A new surface structura approach to ion adsorption: Tracing the location of electrolyte ions. J Colloid Interface Sci 293: 312-321.

18. López-García JJ, Grosse C, Horno J (2009) On the use of the Stern-layer and the charged-layer formalisms for the interpretation of dielectric and electrokinetic properties of colloidal suspensions. J Colloid Interface Sci 329: 384-389.

19. Van Hacker JT, Delanghe JR, Langlois MR, Taes YE, de Buyzere ML, et al (2001) Automated Flow Cytometric Analysis of Cerebrospinal Fluid. Clin Chem 47: $556-560$

20. Gupta AK, Coelho D, Adler PM (2007) Influence of the Stern layer on electrokinetic phenomena in porous media. J Colloid Interface Sci 316: 140159.

21. Lim J, Whitcomb J, Boyd J, Varghese J (2007) Transient finite element analysis of electric double layer using Nernst-Planck-Poisson equations with a modified Stern layer. J Colloid Interface Sci 305: 159-174 